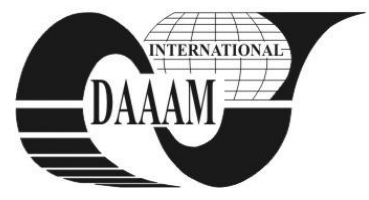

Annals of DAAAM for 2011 \& Proceedings of the 22nd International DAAAM Symposium, Volume 22, No. 1, ISSN 1726-9679 ISBN 978-3-901509-83-4, Editor B. Katalinic, Published by DAAAM International, Vienna, Austria, EU, 2011 Make Harmony between Technology and Nature, and Your Mind will Fly Free as a Bird Annals \& Proceedings of DAAAM International 2011

\title{
CHOICE OF VARIANT OF MANUFACTURING PROCESS WITH ESTIMATION OF COST PRODUCTION
}

\author{
CHWASTYK, P[iotr] \& KOLOSOWSKI, M[ariusz]
}

\begin{abstract}
Planning of manufacturing processes is very urgent element of production process. Choice of right variant of manufacturing process influence on cost production. This work is devoted to this question by pointing the method of selection a variant of the manufacturing process for designing elements belonging to the existing family with cost estimate of production. To choose a variant of the manufacturing process has been proposed the method of cluster analysis.

Key words: manufacturing processes, cost estimation, cluster analysis, CAD, CAM
\end{abstract}

\section{INTRODUCTION}

The principal aim of the company's business is the manufacture of high quality products, produce in many varieties with the lowest costs. To achieve these aims is necessary to apply the optimization of the enterprise's activities. Among the methods of optimization, the particular importance has a method of optimize manufacturing processes. It includes an optimization structure of process (structural optimization), and optimization a conditions of treatment (parametric optimization) (Pajak \& Wieczorkowski, 1982). Because exist a simple relationship between the structure of technological process and conditions (parameters) of treatment, it is necessary to conduct iterative process search optimal solutions. Parametric optimization is concerned with the choice of treatment parameters such as: speed, feed and depth. The value of optimal these parameters allow to achieve, in the particular conditions, extreme value according to optimization criterion. The most common criteria for the optimization of concern: working time depending on the parameters of cutting, the costs of the operation - dependent on parameters of cutting, relationship of time and costs of the operation, referred to the secondary criterion. Structural optimization concerns the optimal distribution of technological process on the operations of specific treatment. Consists in determining the order of operations in the process in such a way as to obtain the required properties of the product, subject to the requirements relating to the achievement an extrema of the relevant criterion. In the case, when you are designing an part belongs to an existing series of products, application of the complicated procedures of optimization is unnecessary given that the other members of this family have been produced on the basis of the processes considered optimal. The similarity of designed elements belongs to series of products allows to apply an existing variant of the manufacturing process used in production (Chwastyk, 2007).

\section{THE CHOICE OF THE VARIANT OF THE MANUFACTURING PROCESS USING THE CLUSTER ANALYSIS}

There are several different alternative manufacturing processes in the manufacturing process. The differences are both: structural and parametric. Structural differences in the manufacturing process are associated primarily with the kind of stock and differences in the structure of the elements belonging to the groups of dimension in the family. On the parametric differences between processes decisive influence: type of machine tools, tools and parameters of treatment.

The researches were based on an analysis the variants of the manufacturing process for family of products of valve spindle. The differences in technological processes these elements are associated with the carrying out of the technological operations on different machines and in the case of the implementation of the different methods a treatment of thread. These differences are a structural nature.

The choice of the optimal variant the manufacturing process is carried out due to the costs incurred as a result of its implementation. In order to determine which of the existing variants is the most optimal in terms of costs was proposed an analysis the formation of agglomerates (cluster analysis) (Han \& Kamber, 2000), which is searching of data groupings in multidimensional space. Criterion of selection of manufacturing process, according to the requirements of quality, are a cost and time of treatment. The researches shows that each element has the attributes have a significant impact on the cost of production process. This may be his characteristics geometrical, accuracy, quality, etc. In the case a group of parts with high similarity of construction, as in the case of elements belonging to the type of series, the decisive influence on their cost of manufacturing have the main geometrical dimensions. Examples of such elements can be the type of series of valve spindle (fig. 1).

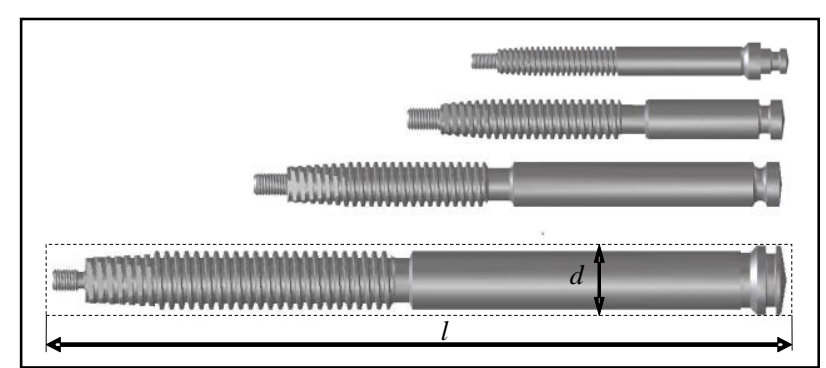

Fig. 1.Selected elements of a type of series of valve spindle $(d, l$ - diameter and length of the stock)

These elements have large structural similarity, as shown, by their shape and the accuracy of the implementation. The differences are primarily in geometric dimensions. The basis for the cluster analysis in a given class of parts is to collect data on costs and times for parts produced in every variants of the manufacturing process. In the case when designating factors for example the cost of manufacturing are the diameter $d$ and length $l$, and the determinant of the selection process we use only cost criterion, we have the situation shown in the figure. 2. The data presented in the chart appear in the groups (clusters). In the area of cluster are these data, for which the difference in the important parameters (cost) does not exceed the established threshold, for example. $10 \%$ in relation to the center of cluster. 
In determining the formation of agglomerates data apply method of k-means. Measures shall be determined by using the agglomerates expressions:

$$
\begin{gathered}
x=\frac{1}{n}\left(x_{1}+x_{2}+\cdots+x_{n}\right), y=\frac{1}{n}\left(y_{1}+y_{2}+\cdots+y_{n}\right), \\
z=\frac{1}{n}\left(z_{1}+z_{2}+\cdots+z_{n}\right)
\end{gathered}
$$

Selection of optimum variant process is chosen in this case on the basis of size $d$ and $l$.

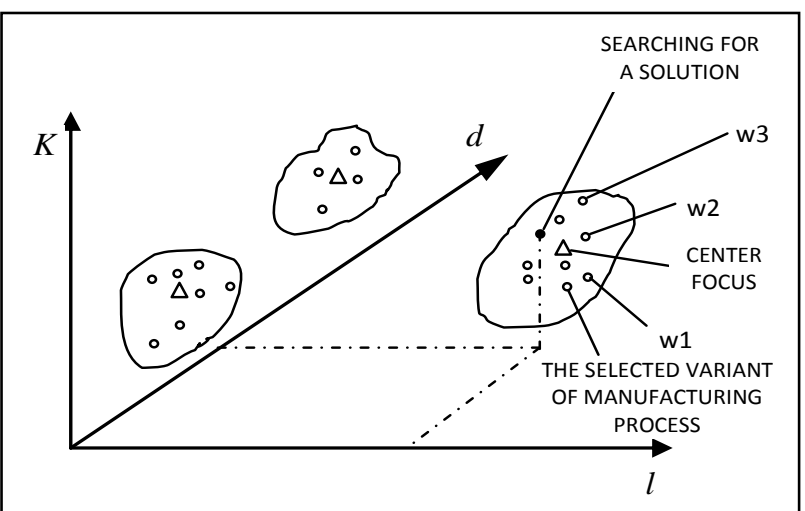

Fig. 2. The idea of the method of choice a variant of the manufacturing process using the cluster analysis from the point of view of the criterion of cost $K$ to parameters $d$ and $l$

If we are in the border existing cluster, select variant process belonging to the cluster that have the lowest cost with all variants that make up this cluster. Membership of a given cluster can be determined by distance from its centre. This distance may be described by Euclidean distance. If $X=\left(x_{1}, x_{2}, \ldots, x_{i}\right)$ where $X$ is the set of elements in multidimensional space, and $Y=\left(y_{1}, y_{2}, \ldots, y_{j}\right)$ is a collection of existing cluster in the same space, the distance $x_{i}$ from the center focus point $y_{i}$ is expressed by the formula:

$$
d\left(x_{i}, y_{i}=\sqrt{\left(x_{i}-y_{i}\right)^{2}}\right.
$$

In the absence of opportunities to find suitable focus you need to develop a new variant of the manufacturing process.

\section{COST ESTIMATION}

Proposed in this study the methodology can specify the cost of production of the designed parts. Is based on data describing the construction of the element presented in model developed in the CAD system using the features method. Features defined in construction process describe not only the geometrical form of element, but also indicate their qualitative characteristics and type of treatment. In addition to the data received from the design process, the basis for estimating the cost of production is variant of the manufacturing process determined in cluster analysis. The individual stages in the process of estimating costs are according to the model shown in Figure 3. Process cost estimate requires additional of data: machinery, tools and parameters of treatment. These data are taken from the prepared databases and provide the basis for calculating the times of individual operations, which sum shall be made on time execution of the entire manufacturing process. The time of the manufacturing process is used to calculate the direct costs. The next step is the estimation of indirect costs. To do this, we use one of the methods of calculation of the cost. Selection of the appropriate method depends on the nature of production (Matuszek, 2000). For cost estimation of presented products a method of additional calculation was proposed. Such a choice was made because of the production of many different products on workstations with different values.

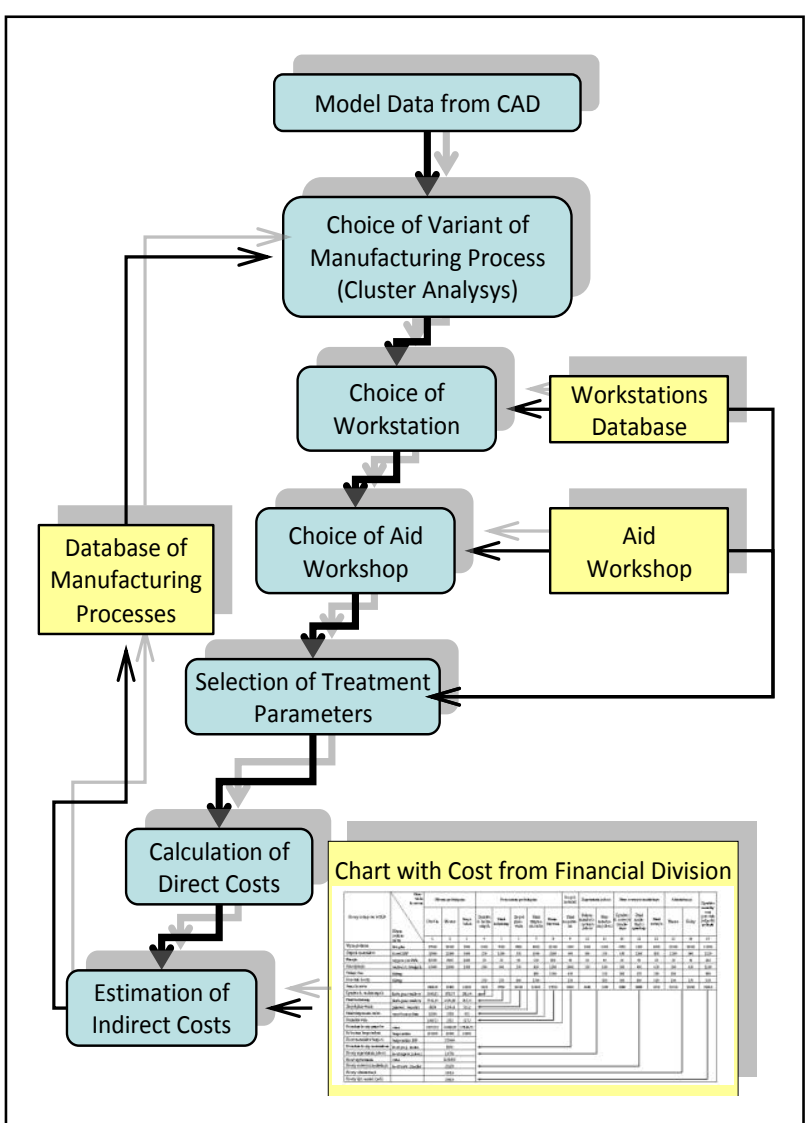

Fig. 3. Model of estimating the cost of manufacturing

The estimation of indirect costs is carried out using the allocation keys (Chwastyk, 2010) which are calculated according to financial information about companies costs incurred within a specified period of time in the past.

\section{CONCLUSION}

The proposed methodology allows to choice an optimal, because of the costs, variant of the manufacturing process in the design stage. Cost's information enable to quickly assess the profitability of production and the possibility of realization of customer orders. The method gives also the possibility to compare alternative manufacturing processes and choose a process, which, at that time, will be beneficial for the company according to the current production plan. The proposed method can be used only if in the enterprise exist an integrated $\mathrm{CAD} / \mathrm{CAM}$ system and access to up-to-date financial information company. This ensures a high accuracy of the results.

\section{REFERENCES}

Chwastyk P. (2007): Features Method in Process of CAD/CAM Integration. Mechanik No. 11/2007, pp. 954-955. ISSN 0025-6552

Chwastyk P. (2010): Using of Features in Process of Cost Estimation of Product. Mechanik No. 1/2010/S, pp. 22-29. ISSN 0025-6552

Pajak E., Wieczorowski K. (1982): Podstawy optymalizacji operacji technologicznych w przykladach. Wydawnictwa Naukowe PWN, Warszawa-Poznań 1982

Han J., Kamber M. (2000): Data Mining: Concepts and Techniques. Morgan Kaufmann Publishers

Matuszek J. (2000) Production engineering, Publishing Hause of Technical University of Lodz, ISBN 83-87087-97-1, Bielsko-Biala 